\title{
The Progressive Effects of Built Environments on Supporting Physical Activity Diversity in High- Density Areas: A Case Study in Shenzhen, China
}

\section{Yuan Gao}

Harbin Institute of Technology

Kun Liu ( $\nabla$ liuk@hit.edu.cn )

Harbin Institute of Technology

Peiling Zhou

Harbin Institute of Technology

Hongkun Xie

Gemdale Group South China Real Estate Company

\section{Research Article}

Keywords: Physical activity diversity, Built environment, progressive effects, Healthy city, High-density city

Posted Date: January 28th, 2021

DOI: https://doi.org/10.21203/rs.3.rs-150658/v1

License: (c) This work is licensed under a Creative Commons Attribution 4.0 International License. Read Full License 


\section{Abstract}

Background: Physical activity diversity (PAD) is an essential indicator to present the vitality of health city, and how to improve PAD from the built environment perspective is a key issue for healthy urban planning and design, especially in high-density cities;

Methods: This study selected Shenzhen, China as a representative case, combined the diversity of PA participants, types and occurrence times for the comprehensive understanding of PAD, fully used multiple source data for the measurement and statistical analysis of PAD and built environments, to discover the relationships between the built environment and PAD, and to explore the different effects in clustered and sprawled high-density urban forms;

Results: PAD was unevenly distributed in Shenzhen, higher in the clustered areas and lower in the sprawled ares and the effects of the built environment on PAD were significantly different between two kinds of areas;

Conclusions: the built environment supports PAD by progressive effects, in which accessibility is the necessary and funda-mental condition to activate individual PAs, inclusiveness is sufficiently supports the coaction of various kind of PAs to consolidate PAD, and landscape attractiveness furtherly aggregates more PAs to achieve higher PAD. To create accessible, inclusive, and attractive built environments are crucial ways to improve the vitality of healthy city development in high-density cities.

\section{Introduction}

With humanity entering "the post-medicine era", researchers in the field of urban planning have begun to refocus their attention on public health issues [1-3]. Exploring planning and design strategies that effectively support and stimulate physical activity (PA) has become increasingly popular. However, most of the existing research focuses on the supporting role of the built environment on individual PA and ignores PA diversity (PAD) as an integrative characteristic to present health vitality. Urban scholars have actually been paying attention to diversity for a long time. Jocobs believed that the diversity of a city is one of its essential attributes, and the lack of diversity would reduce or stifle intergroup contact and caused social and ethnic divisions [4]. Thompson proposed that an urban public space's core contribution in the 21 st century should be to show the diversity of individuals and cultures [5]. Scholars generally believe that diversity is a necessary guarantee for the system to maintain its functions and processes [6]. Similarly, PAD is an important indicator of sustainable healthy behaviors and social vitality and exploring the supporting role of the built environment for PAD should be an important topic for healthy city studies.

Diversity refers to the abundance of things. In the field of ecology, diversity has multi-dimensional connotations such as genetics, species, and ecosystems. It is a general term for multi-level and multiple life forms in biological systems. The connotation of diversity is quite rich and should be defined in various dimensions based on the re-search object. PA is a kind of human activity that uses muscles to generate energy consumption. It contains dimensions such as the activity groups, types, and processes. 
When discussing various kinds of PA, current research mainly focuses on the multiple classes and ethnic groups from a social equity perspective [7], or multiple types such as walking and cycling [8]. These studies all mention PA's heterogeneous characteristics but have not yet measured PA from a more integrated perspective of diversity. To de-scribe PAD, comprehensive measurements should be carried out by integrating a variety of PA's key characteristics.

In the existing research on the correlation between the built environment and PA, the types of PA mainly include walking, jogging, and cycling [9], and activity groups include gender, age, race, and others. Reviews of relevant research found that there were many common and different impacts of the built environment on different PA types and groups. First of all, accessibility has been commonly believed to support all kinds of PA [10,11], in which accessibility to service facilities and public transit positively supports walking and jogging [12-14], and the density of pedestrians and inter-sections can promote the presence of PA [15,16], and inspire multiple social classes' PA [17]. Secondly, the utilitarian aspects of the built environment such as mixed land use and population density have also been proved to positively support PA, not only to improve the frequency of individual PA and urban vitality [18-20], but also to provide an even amount of activity places for diverse PA participants [21-24]. Further, studies have shown that built environments also promote gatherings for PA by providing inclusive places and increasing sports facilities [25-28]. Meanwhile, the landscape attractiveness of the built environment, such as places with many scenic spots and a high amount of green coverage, can continuously attract more kinds of PA effectively $[26,29]$.

To sum up, accessibility is a common feature of the built environment that sup-ports almost all kinds of $\mathrm{PA}$, and the utility of the built environment provide greater possibilities for PAs' occurrence. The inclusiveness of the place serves for co-action of multiple PAs, and the landscape could attract various people and activities. To achieve PAD, the accessibility and utility of the built environment should be the necessary conditions to basically support individual PA, and inclusion and landscape attractive-ness might be the sufficient conditions to gather various kinds of PA.

In Asia, rapid economic development, large populations, and scarce land create many high-density cities. However, contrary to mainstream research results from Western countries to which advocate the health benefits of density, Asian cities have not achieved better public health outcomes. In the past 30 years, PA in Asia has been declining linearly [30], far below the world average level. Some studies also have found that lower residential density is likely to promote PA in China [31,32]. Therefore, the consensus of European and American scholars may not be suitable for Asian high-density cities [33], and the discussion of high-density cities should be rooted in their local socio-economic and urban form characteristics, with critical use of Western research results.

Shenzhen was selected for this study as a representative high-density metropolis case in Asia. Volunteered Geographic Information (VGI) of PA and multi-source big data were used to define and measure the PAD and the built environment. The study aimed to explore the association between the built 
environment and PAD in a high-density city and to propose urban planning strategies to support PAD for the inclusive and sustained well-being of citizens.

\section{Methods}

\subsection{Study area}

Shenzhen is located in the Pearl River Delta region of southern China, close to Hong Kong. It was the first city to open up city as part of China's reform policy and is one of the core cities in the Guangdong-Hong Kong-Macao Greater Bay Area. Statistics from 2017 show that Shenzhen has an administrative area of $1997.27 \mathrm{~km}^{2}$, including $975.5 \mathrm{~km}^{2}$ for construction, with a service population of 20 million people. It is the city with the smallest area and largest population among all metropolises in China.

Shenzhen was established as a city in 1980, starting from the Shenzhen Special Economic Zone (SEZ) which was around $327.5 \mathrm{~km}^{2}$, and commonly referred to as "the Inside Shenzhen". The SEZ has carried out top-down urban construction as part of the overall urban planning, forming a sparse and orderly banded-cluster structure. Each cluster has mixed land-use and, street networks and is bordered by natural elements such as rivers and mountains. Meanwhile, regarding "the Outside Shenzhen" around SEZ, the remaining land, covering more than $1,600 \mathrm{~km}^{2}$, was built up following a dis-ordered bottom-up way, with rapid urban sprawl along external traffic corridors. Due to the lack of planning management early on, street networks and public services are relatively poorer than those in SEZ. As a result, two distinct urban forms have been shaped: clustered and sprawled. As shows in Figure 1, these two kind of urban forms provided two typical high-density built environment samples for this research.

\subsection{Research design}

Based on the comprehensive understanding of diversity, this research defined PAD as an integrated characteristic of PA's richness in terms of PA participants, PA type, and PA occurrence time. We hypothesized that, the built environment supports PAD by four progressive steps, as shows in Figure 2: accessibility for people to do PA, a utilitarian environment to improve the possibilities of PA, inclusiveness to support the co-action of various PAs, and landscape attractiveness to gather various PAs. At the same time, we hypothesized that the effects of the built environment to support PAD were different between clustered and sprawled high-density urban forms.

\subsection{Data resources}

\subsubsection{PA data}

In this study, the PA data were collected from Codoon, one of China's most popular self-tracking applications. With Codoon, people can track PA information (including the type of activity, time, speed, duration, routes, etc.), and upload, share, and compare their workouts on social network platforms, which forms a natural VGI data pool. Considering that PA mostly occurred in April and July, 4-day data from 
April and 4-day data from July 2015 were selected for this study, including two workdays and two weekends. Routes which started or finished in residential areas were chosen, to identify the social class of PA participants by housing price. There were 735 data, including 194 walking, 486 jogging, and 55 cycling data.

\subsubsection{Built environment data}

The built environment data included the following: the Shenzhen Land-Use Sur-vey (2014), in which land was classified to nine types (residential land, commercial land, government, and institutional land, industrial land, warehouse land, street land, infrastructure land, parklands, and other lands), street network from the Open Street Map, including five types (motorway, primary, secondary, branch, and others); bus stop data from Baidu Map Point of Interest (2012); greenway networks from the Shenzhen Greenway Map (2013); sports facilities and scenic spots from the Scott Map (2016); and house prices from Home Link, which is one of the most popular real estate transaction platforms in China.

\subsection{Measurements}

\subsubsection{Measurements Unit}

In order to measure the characteristics of PA diversity and the impact of the built environment on it, a $500 \mathrm{~m} 2$ grid [31] was used to present the characteristics of the PA diversity and to explore the influence of the built environment on it $[34,35]$. By using the Fishnet Tool in ArcGIS, land in Shenzhen was divided into grids, and those without PA were excluded, which left 2049 grids.

\subsubsection{Dependent variable}

Based on the integrative definition, PAD was measured as the sum of PA participant diversity (PAPD), PA type diversity (PATD), and PA occurrence time diversity (PAOD). An entropy index was used as a calculation tool for diversity [36], which varied between 0 and 1 ( 0 for maximum specialization, 1 for maximum diversification). PAPD was defined as the mixture of participants of lower-income, low-income, middle-income, and high-income classes [37]; PATD was the richness of different activities including walking, jogging, and cycling; PAOD was used to measure the diverse occurrence times from morning to night. The measures of PAD are shown in Table 1.

Table 1. Measures of PAD. 


\begin{tabular}{|l|l|}
\hline Type of diversity & Measure \\
\hline PAD & $P A D=P A P D+P A T D+P A O D$ \\
\hline PAPD & $\begin{array}{l}\text { PAPD }=\frac{\left\{-\sum_{k_{k}}\left[\left(p_{1}\right)\left(\ln p_{1}\right)\right]\right\}}{\ln k_{1}} \\
\text { where } k=\text { number of social class types, according to income }(k=4: \\
\text { lower-income class, low-income class, middle-income class, high-income } \\
\text { class }) ; p_{1}=\text { total number of type } i \text { multiplied by total number for all PA } \\
\text { participants. }\end{array}$ \\
\hline PATD & $\begin{array}{l}\text { PATD }=\frac{\left\{-\sum_{k_{2}}\left[\left(p_{2}\right)\left(\ln p_{2}\right)\right]\right\}}{\ln k_{2}} \\
\text { where } k_{2}=\text { number of physical activity types }(k=3: \text { cycling, walking, jogging); } \\
p_{2}=\text { total number of type } 2 \text { multiplied by total number for all PA types }\end{array}$ \\
\hline PAOD $=\frac{\left\{-\sum_{k_{5}}\left[\left(p_{3}\right)\left(\ln p_{3}\right)\right]\right\}}{\ln k_{3}}$ \\
PAOD \\
$\begin{array}{l}\text { where } k_{3}=\text { number of physical activity times }(k=4: \text { from } 00: 00 \text { to } 06: 00, \text { from } \\
06: 00 \text { to } 12: 00, \text { from } 12: 00 \text { to } 18: 00, \text { from } 18: 00 \text { to } 24: 00) ; p_{3}=\text { total time of } \\
\text { type } 3 \text { multiplied by total distance for all PA times. }\end{array}$ \\
\hline
\end{tabular}

\subsubsection{Independent variables}

According to the hypothesis, built environment were measured from four aspects: accessibility, utility, inclusiveness and landscape attractiveness. Accessibility contained street network density [15-17, 25], bus stop station density [12], and service facility density [13, 14], which can represent the accessibility of potential destinations in a city. Utility contained population density [22,38,39], the proportion of commercial land [40], and the land use mixture [24-26, 41], which can directly reflect the utility of a built environment. Inclusiveness contained greenway network density [23] and sport facility density [41], which were built to support diverse PAs. Landscape attractiveness contained green land ratio [29] and scenic spot density $[4,42]$. Indicators and measures are shown in Table 2.

Table 2. The Variables and measures of built environment. 


\begin{tabular}{|c|c|c|}
\hline Character & Variable & Measure \\
\hline \multirow[t]{3}{*}{ Accessibility } & $\begin{array}{l}\text { Street } \\
\text { network } \\
\text { density }\end{array}$ & The total length of street per unit area \\
\hline & $\begin{array}{l}\text { Bus station } \\
\text { density }\end{array}$ & Number of bus stops per unit area \\
\hline & $\begin{array}{l}\text { Service } \\
\text { facility } \\
\text { density }\end{array}$ & Number of service facilities per unit area \\
\hline \multirow[t]{3}{*}{ Utility } & $\begin{array}{l}\text { Population } \\
\text { density }\end{array}$ & $\begin{array}{l}\text { The ratio of residential building area to total building area per unit } \\
\text { area }\end{array}$ \\
\hline & $\begin{array}{l}\text { The } \\
\text { proportion of } \\
\text { commercial } \\
\text { land }\end{array}$ & The ratio of commercial land to total land per unit area \\
\hline & $\begin{array}{l}\text { Land use } \\
\text { mixture }\end{array}$ & $\begin{array}{l}\text { An entropy index was used to calculate the land-use mixture, which } \\
\text { varied between } 0 \text { and } 1 \text { ( } 0 \text { for maximum specialization, } 1 \text { for } \\
\text { maximum diversification) }\end{array}$ \\
\hline \multirow[t]{2}{*}{ Inclusiveness } & $\begin{array}{l}\text { Greenway } \\
\text { network } \\
\text { density }\end{array}$ & Length of greenway network per unit area \\
\hline & $\begin{array}{l}\text { Sport facility } \\
\text { density }\end{array}$ & Number of sport facilities per unit area \\
\hline \multirow[t]{2}{*}{$\begin{array}{l}\text { Landscape } \\
\text { attractiveness }\end{array}$} & $\begin{array}{l}\text { Green space } \\
\text { ratio }\end{array}$ & The proportion of green space per unit area \\
\hline & $\begin{array}{l}\text { Scenic spot } \\
\text { density }\end{array}$ & Number of scenic spots per unit area \\
\hline
\end{tabular}

\subsubsection{Dependent variable}

Considering that PA is affected by seasons and holidays, two control variables were selected: air temperature ( 1 for $28{ }^{\circ} \mathrm{C}$ and below, 0 for above $28^{\circ} \mathrm{C}$ ), and weekend or not ( 1 for weekend, 0 for weekday) [43]. PA data obtained from the Internet did not contain individual attributes, so personal factors are not discussed in this paper.

\subsection{Data merging and statistical analysis}

The PA and built environment data were overlaid in ArcGIS 10 with the Shenzhen local coordinate system to form the database. SPSS was used for statistical and regression analyses to establish multivariate linear regression models to explore the association between PAD and the built environment. Three models were built up for overall, clustered and sprawled urban area separately (Table 3). Collinearity diagnostics 
among the independent and control variables were performed before modeling, and the result showed no strong associations among the variables (VIF <10).

Table 3. Regression models and the hypothesized effect.

\begin{tabular}{|c|c|c|c|c|c|}
\hline & & & Model & Model 2 & Model 3 \\
\hline & & & & $\begin{array}{l}\text { Clustered } \\
\text { area }\end{array}$ & $\begin{array}{l}\text { Sprawled } \\
\text { area }\end{array}$ \\
\hline Dependent va & & & PAD & & \\
\hline Regression $\mathrm{m}$ & & & $\begin{array}{l}\text { Multivari } \\
\text { model }\end{array}$ & te linear re & ession \\
\hline Number of un & & & 2049 & & \\
\hline Hypothesized & & & & & \\
\hline Independent & Accessibility & Street network density & Positive & Positive & Positive \\
\hline & & Bus station density & Positive & Positive & Positive \\
\hline & & Service facility density & Positive & Positive & Positive \\
\hline & Utility & Population density & Positive & Positive & Positive \\
\hline & & $\begin{array}{l}\text { The proportion of } \\
\text { commercial land }\end{array}$ & Positive & Positive & Positive \\
\hline & & Land use mixture & Positive & Positive & Positive \\
\hline & Inclusiveness & $\begin{array}{l}\text { Greenway network } \\
\text { density }\end{array}$ & Positive & Positive & Positive \\
\hline & & Sports facility density & Positive & Positive & Positive \\
\hline & Landscape & Green space ratio & Positive & Positive & Positive \\
\hline & & Scenic spot density & Positive & Positive & Positive \\
\hline Control & Temprature $\leq 28$ & & Positive & Positive & Positive \\
\hline & Weekend & & Positive & Positive & Positive \\
\hline
\end{tabular}

\section{Results}

3.1 Descriptive characteristics

\subsubsection{PAD and the distribution}

Among the 2049 spatial units, the mean value of PAD was 0.25 , which indicates low diversity all over Shenzhen. Comparing PAD in clustered and sprawled areas, we found the PAs in clustered areas were 2 
times more diverse than those in sprawled ones. Figure 3 shows that PAD is unevenly distributed in Shenzhen. The most diverse PAs are widely spread and have line-like aggregation in clustered areas along seasides and rivers, within big parks and downtown. In the sprawled area, there are fewer units with diverse PAs and they show spot-like aggregation in the downtown area.

Table 4. The description of PAD.

\begin{tabular}{|c|c|c|c|c|}
\hline & PAD & & & \\
\hline Overall & Mean & Maximum & Minimum & Standard Deviation \\
\hline Clustered area & 0.2497 & 0.9000 & 0.0000 & 0.2683 \\
\hline Sprawled area & 0.3892 & 0.9000 & 0.0000 & 0.2780 \\
\hline Overall & 0.1624 & 0.8400 & 0.0000 & 0.2212 \\
\hline
\end{tabular}

\subsubsection{The characteristics of the built environment}

Statistical analysis shows the similarities and differences of the built environment in clustered and sprawled areas. As shows in Table 5, both areas have a similar population and land use mixture, and because of the strict ecological control system and top-down overall greenway network constructions, the density of green resources and greenways are at the same level. The clustered area is more accessible and has much richer public facilities and scenic spots than the sprawled area. In the clustered area, each cluster is net-work-organized with complete facilities to form a self-sufficient unit, and clusters are divided by rivers, hills and green belts to maintain many scenic spots. In the sprawled area, construction lands have been quickly expanded and there is a lack of overall transportation and facility planning, which has resulted in poor accessibility and in-sufficient facilities.

Table 5. The description of PAD. 


\begin{tabular}{|c|c|c|c|c|c|}
\hline & & & Overall & $\begin{array}{l}\text { Clustered } \\
\text { area }\end{array}$ & $\begin{array}{l}\text { Sprawled } \\
\text { area }\end{array}$ \\
\hline \multirow[t]{10}{*}{ Indicators } & \multirow[t]{3}{*}{ Accessibility } & Street network density & 8.484 & 12.220 & 6.141 \\
\hline & & Bus station density & 54.330 & 69.389 & 44.901 \\
\hline & & Service facility density & 32.015 & 39.849 & 27.110 \\
\hline & \multirow[t]{3}{*}{ Utility } & Population density & 0.071 & 0.066 & 0.073 \\
\hline & & $\begin{array}{l}\text { The proportion of } \\
\text { commercial land }\end{array}$ & 0.033 & 0.045 & 0.026 \\
\hline & & Land use mixture & 0.454 & 0.468 & 0.446 \\
\hline & \multirow[t]{2}{*}{ Inclusiveness } & Greenway network density & 1.729 & 1.784 & 1.695 \\
\hline & & Sports facility density & 8.562 & 12.068 & 6.367 \\
\hline & \multirow{2}{*}{$\begin{array}{l}\text { Landscape } \\
\text { attractiveness }\end{array}$} & Green space ratio & 0.208 & 0.206 & 0.209 \\
\hline & & Scenic spot density & 2.308 & 4.313 & 1.053 \\
\hline
\end{tabular}

\subsection{Statistical modelling results}

Three multivariate linear regression models were developed separately for over-all, clustered, and sprawled areas to explain and compare the relations between the built environment and PAD. The adjusted R squared presents the goodness of fit in the three models.

Table 6 shows the different results among the three models. In model 1, accessibility, inclusiveness and landscape attractiveness were all positively related with PAD, and utility partly had negative effects. Comparing the results of models 2 and 3 , the accessibility and utility of the built environment were closely associated with PAD in the sprawled area, and slightly affected PAD in the clustered area. While inclusiveness and landscape attractiveness positively related with PAD in the clustered area, they contributed little to diversity in the sprawled area. In detail, PAD in the clustered area was positively associated with green space ratio, greenway network density, sports facility density, and scenic spot density, and was negatively associated with land use mixture. PAD in the sprawled area was positively associated with street network density, bus station density, service facility density, and greenway network density, and was negatively associated with population density, and the proportion of commercial land.

Table 6. Regression models and results. 


\begin{tabular}{|c|c|c|c|c|c|c|c|c|}
\hline \multicolumn{3}{|c|}{ Regression model } & \multicolumn{2}{|c|}{$\begin{array}{l}\text { Model } 1 \\
\text { Overall }\end{array}$} & \multicolumn{2}{|c|}{$\begin{array}{l}\text { Model } 2 \\
\text { Clustered area }\end{array}$} & \multicolumn{2}{|c|}{$\begin{array}{l}\text { Model } 3 \\
\text { Sprawled area }\end{array}$} \\
\hline & & & B & Sig. & B & Sig. & B & Sig. \\
\hline \multirow[t]{12}{*}{$\begin{array}{l}\text { Independent } \\
\text { variables }\end{array}$} & \multirow[t]{3}{*}{ Accessibility } & $\begin{array}{l}\text { Street } \\
\text { network } \\
\text { density }\end{array}$ & 0.007 & 0.000 & 0.002 & 0.203 & 0.007 & 0.000 \\
\hline & & $\begin{array}{l}\text { Bus station } \\
\text { density }\end{array}$ & 0.000 & 0.002 & 0.000 & 0.126 & 0.000 & 0.024 \\
\hline & & $\begin{array}{l}\text { Service } \\
\text { facility } \\
\text { density }\end{array}$ & 0.001 & 0.000 & 0.000 & 0.272 & 0.001 & 0.000 \\
\hline & \multirow[t]{3}{*}{ Utility } & $\begin{array}{l}\text { Population } \\
\text { density }\end{array}$ & -0.204 & 0.014 & -0.111 & 0.430 & -0.230 & 0.018 \\
\hline & & $\begin{array}{l}\text { The } \\
\text { proportion } \\
\text { of } \\
\text { commercial } \\
\text { land }\end{array}$ & -0.099 & 0.192 & 0.030 & 0.759 & -0.384 & 0.001 \\
\hline & & $\begin{array}{l}\text { Land use } \\
\text { mixture }\end{array}$ & -0.057 & 0.087 & -0.165 & 0.002 & 0.038 & 0.318 \\
\hline & \multirow[t]{2}{*}{ Inclusiveness } & $\begin{array}{l}\text { Greenway } \\
\text { network } \\
\text { density }\end{array}$ & 0.017 & 0.000 & 0.038 & 0.000 & 0.008 & 0.043 \\
\hline & & $\begin{array}{l}\text { sports } \\
\text { facility } \\
\text { density }\end{array}$ & 0.001 & 0.002 & 0.002 & 0.001 & 0.000 & 0.916 \\
\hline & \multirow[t]{2}{*}{$\begin{array}{l}\text { Landscape } \\
\text { Attractiveness }\end{array}$} & $\begin{array}{l}\text { Green } \\
\text { space ratio }\end{array}$ & 0.068 & 0.004 & 0.079 & 0.043 & 0.020 & 0.462 \\
\hline & & $\begin{array}{l}\text { Scenic spot } \\
\text { density }\end{array}$ & 0.002 & 0.000 & 0.001 & 0.012 & 0.002 & 0.273 \\
\hline & \multicolumn{2}{|l|}{ Weekend } & 0.141 & 0.000 & 0.213 & 0.000 & 0.083 & 0.000 \\
\hline & \multicolumn{2}{|l|}{ Spring } & 0.142 & 0.000 & 0.158 & 0.000 & 0.119 & 0.000 \\
\hline \multicolumn{3}{|l|}{ Constant } & -0.023 & 0.236 & 0.056 & 0.112 & -0.028 & 0.191 \\
\hline \multicolumn{3}{|c|}{ Adjusted R square } & 0.372 & & 0.366 & & 0.296 & \\
\hline
\end{tabular}

Table 7. Regression models and results. 


\begin{tabular}{|lllllll|}
\hline \multicolumn{3}{|c|}{ Clustered area } & \multicolumn{5}{l|}{ Sprawled area } \\
\cline { 2 - 5 } & $\begin{array}{l}\text { Street } \\
\text { network } \\
\text { density }\end{array}$ & $\begin{array}{l}\text { Bus station } \\
\text { density }\end{array}$ & $\begin{array}{l}\text { Service } \\
\text { facility } \\
\text { density }\end{array}$ & $\begin{array}{l}\text { Street } \\
\text { network } \\
\text { density }\end{array}$ & $\begin{array}{l}\text { Bus station } \\
\text { density }\end{array}$ & $\begin{array}{l}\text { Service } \\
\text { facility } \\
\text { density }\end{array}$ \\
\hline $\begin{array}{l}\text { High } \\
\text { PAD }\end{array}$ & 12.97 & 75.80 & 41.47 & 10.57 & 73.64 & 47.02 \\
\hline $\begin{array}{l}\text { Low } \\
\text { PAD }\end{array}$ & 11.69 & 64.80 & 38.69 & 5.51 & 40.78 & 24.26 \\
\hline
\end{tabular}

\section{Discussion}

\subsection{Statistical modelling results}

The results shows that the accessibility of the built environment is positively associated with PAD in the overall and sprawled areas, which indicates the significance of street network density, bus stop density, and service facility density for supporting di-verse and vital physical activities. However, this relationship was not significant in the clustered area. Is accessibility not important in clustered areas?

As shown in Table 4, the accessibility of the built environment in the clustered area is much higher than that of the sprawled area. Taking 0.5 as the dividing point, the PAD was divided into high and low parts, and the accessibility indicators were counted and compared respectively in two kinds of areas (Table 7). In the clustered area, there was no significant gap of accessibility between high PAD and low PAD, and the accessibility with low PAD was almost at the same level as ones with high PAD in the sprawled area. However, the gap of accessibility was large between high PAD and low PAD in the sprawled area. This is because of the generally high accessibility, so there were no significant relations between accessibility and PAD in the clustered area, which indicates that the built environment had met the necessary conditions of accessibility to activate various physical activities.

\subsection{The negative effects of utility on PAD}

The results show that the utility of the built environment is negatively correlated with PAD, in which landuse mixture reduced PAD in the clustered area, and population density and the proportion of commercial land had negative effects on PAD in the sprawled area. Preliminary research has shown that commercial services could enhance individual travel and induce individual PA [44]. However, dense and mixed-use built environments are often located downtown, where it is difficult to provide enough space to gather for various PAs. Meanwhile, the fast-food industry had permeated the business world in recent years, and has probably been rejected by PA groups, whose main goal is to improve their health. Up to now, dense and mixed-use blocks have failed to attract various PAs to achieve healthy vitality.

\subsection{The co-action effects of inclusiveness on PAs}


In both clustered and sprawled areas, greenway network density was found to play a significant role in promoting PAD. A greenway is a linear public space that facilitates citizens to get close to natural resources such as rivers, lakes, and mountains [45], and it is generally designed for popular PAs such as walking, jogging and cycling [46].

Since 2010, a total of $2448 \mathrm{~km}$ of greenways has been built, forming a large and homogeneous greenway network all over Shenzhen (Figure 4), which provides, al-most the same opportunities to attract various PAs in both clustered and sprawled areas, and achieves co-action effects to support diverse PAs.

In addition, sports facility density was found to promote PAD in the clustered area, while it had no effect in the sprawled area. As a professional public service for PAs, sports facilities are undoubtedly capable of attracting diverse PAs. Limited by the weak planning and backward stage of development in the sprawled area, sports facilities are in short supply, thus failing to promote PAD.

\subsection{The aggregation effects of landscape attractiveness on PAD}

In models 1 and 2 , the green space ratio and scenic spot density were positively correlated with the PAD. Overlapping the green lands, scenic spots and PAD (Figure 5), it is clear that places with rich green and scenic spots correspond to high PAD, which shows the clear aggregation effects on diverse PAs. Unlike greenways and sports facilities, which functionally support various PAs, places with good landscapes provide rich visual and mental experiences, so they have become popular destinations that can aggregate diverse PAs. In the sprawled area, green lands are as rich as those in the clustered area, but because of the marginal distribution and poor accessibility, they are hard to reaches and use. Meanwhile, the sparse scenic spots of the built environment result in weak attractiveness, thus failing to gather diverse PAs.

\subsection{The progressive effects of the built environment on PAD}

Based on the above discussion, the progressive effects of the built environment emerge to support PAD (Figure 6). Accessibility is the fundamental and necessary condition to provide possibilities for people to go outside and, then to activate various PAs. Then, inclusive playgrounds such as greenways and sports facilities can functionally support the co-action of various PAs to improve the diversity. Afterwards, the good landscape of the built environment furtherly triggers rich activity experiences to strengthen the aggregation of various PAs, thus resulting in higher PAD. The three built environment characteristics are superimposed, in which the former is a necessary condition for the latter, and the latter is a sufficient condition for the former, to build up a progressive mechanism to support PAD.

4.6 Advantages of clustered area for promoting healthy and vital urban life in high-density cities

An accessible, inclusive and attractive built environment is important to improve PAD and promote the vitality of a healthy city. However, in high density cities, crowded and expanded urban constructions easily results in poor accessibility, scarce public space, and less attractive landscape. Compared with sprawled area, clustered areas have significant advantages for supporting PAD, since the clustered structure successfully controls the scale of urban construction by natural and historical re-sources, which 
then provides sufficient accessible and attractive public space and landscapes to promote various PAs. In high-density cities, maintaining the balance between dense urban construction and landscape reservation, and building up an accessible and inclusive public space system such as a greenway network are crucial for promoting healthy and vital urban life.

\subsection{Limitations}

This study fully utilized big data from multiple sources, including traditional statistics, PA VGI and open source data such as POls and house prices. Because it is difficult to guarantee the same acquisition time of multi-source data, the combined analysis of data might lead to errors, and affect the accuracy of the results. Meanwhile, data providers of PA VGI are probably young and modern people; accordingly, the description and measure of PAs may not be generalized. Further, due to data defects of PA VGI, the individual characteristics of physical activity participants could not be included in the models, resulting in the insufficient explanatory ability of the study.

\section{Conclusion}

PAD is an important concept for presenting healthy and vital urban life, and how to improve PAD from a built environment perspective is a key issue for healthy urban planning and design, especially in highdensity cities. This study combined the diversity of PA participants, types and occurrence times for the comprehensive under-standing and measurement of PAD; discovered progressive relationships between the built environment and PAD; and explored the different effects in different kind of high density urban forms.

As the study has shown, PAD was found to unevenly distribute in Shenzhen, higher in the clustered area and lower in the sprawled area. Based on the results and the above discussion, we conclude that the built environment supports PAD by progressive effects, in which accessibility is the necessary and fundamental condition to activate individual PAs, inclusiveness sufficiently supports the coaction of various PAs to consolidate PAD, and landscape attractiveness further aggregates more PAs to achieve higher PAD. Three characteristics are interrelated, in which the former is a necessary condition for the latter, and the latter is a sufficient condition for the former. Because of the progressive effects of the built environment on PAD, the clustered area showed significant advantages in supporting diversity since the clustered urban form structurally maintains the balance between dense urban construction and landscape reservation, with an accessible and inclusive public space system.

PAD is the comprehensive embodiment of the vitality of a healthy city. To pro-mote health-oriented urban planning and development in high density cities, clustered urban structures should be advocated, and step-forward strategies should be carried out: first, to promote the overall accessibility of the built environment to activate PA; second, to build up an inclusive public space system for the coaction of various PAs; further, to improve the attractiveness of landscapes to aggregate PAs for higher diversity. To sum up, creating an accessible, inclusive, and attractive built environment is a crucial way to improve the vitality of healthy city development in high-density cities. 


\section{Declarations}

\section{Ethics approval and consent to participate}

Not applicable.

\section{Consent for publication}

Not applicable.

\section{Availability of data and materials}

The datasets used and/or analyses during the current study are available from the corresponding author on reasonable request.

The PA data in this study were collected from Codoon, it is one of China's most popular self-tracking applications. Its data is publicly available. Users of Codoon can view the activity information of other users by logging in to the official website and registering an account for free.

\section{Competing interests}

The authors declare that they have no competing interests.

\section{Funding}

This research was funded by the National Natural Science Foundation of China, Grant number 51508126, the National Key Research and Development Program of China, Grant number 2019 YFD1100802 and 2019 YFD1100804.

\section{Authors' contributions}

$\mathrm{KL}$ obtained funding and developed the study protocol. $\mathrm{KL}, \mathrm{YG}$ and $\mathrm{PLZ}$ put forward research concepts. $\mathrm{KL}$ and $Y G$ proposed research method. $\mathrm{HKX}$ collected data. $\mathrm{KL}$ and $\mathrm{YG}$ analysis and interpret the data. $\mathrm{KL}$ and YG drafted the original manuscript. KL and PLZ reviewed manuscript. All authors contributed and approved the final manuscript.

\section{Acknowledgments}

We thank the National Natural Science Foundation of China (Grant No. 51508126) for the support of the study and the preparation of this paper. The research was also partially supported by the National Key Research and Development Program of China, Grant number 2019YFD1100802 and 2019YFD1100804 for physical activity VGI data collection and processing. We also sincerely thank the Editor and reviewers of BMC Public Health for their constructive comments for the paper revision.

\section{References}


1. J. Corburn, Confronting the challenges in reconnecting urban planning and public health, American journal of public health 94(4) (2004) 541-546.

2. S. Jalaladdini, D. Oktay, Urban public spaces and vitality: a socio-spatial analysis in the streets of Cypriot towns, Procedia-Social and Behavioral Sciences 35 (2012) 664-674.

3. M.J. Koohsari, H. Badland, B. Giles-Corti, (Re) Designing the built environment to support physical activity: bringing public health back into urban design and planning, Cities 35 (2013) 294-298.

4. J. Jacobs, The death and life of great American cities, Vintage2016.

5. C.W. Thompson, Urban open space in the 21 st century, Landscape and urban planning 60(2) (2002) 59-72.

6. Z. Zheng, Study on the city eco-construction based on the analysis of space diversity, Tongji University, Shanghai, 2008.

7. R.E. Lee, C. Cubbin, M. Winkleby, Contribution of neighbourhood socioeconomic status and physical activity resources to physical activity among women, Journal of Epidemiology \& Community Health 61(10) (2007) 882-890.

8. S. Mäkelä, S. Aaltonen, T. Korhonen, R.J. Rose, J. Kaprio, Diversity of leisure-time sport activities in adolescence as a predictor of leisure-time physical activity in adulthood, Scandinavian journal of medicine \& science in sports 27(12) (2017) 1902-1912.

9. Y. Wang, C.K. Chau, W. Ng, T. Leung, A review on the effects of physical built environment attributes on enhancing walking and cycling activity levels within residential neighborhoods, Cities 50 (2016) 115.

10. N. Humpel, N. Owen, E. Leslie, Environmental factors associated with adults' participation in physical activity: a review, American journal of preventive medicine 22(3) (2002) 188-199.

11. S.A. Lee, Y.J. Ju, J.E. Lee, I.S. Hyun, J.Y. Nam, K.-T. Han, E.-C. Park, The relationship between sports facility accessibility and physical activity among Korean adults, BMC Public Health 16(1) (2016) 893.

12. Z. Wang, C. Lee, Site and neighborhood environments for walking among older adults, Health \& Place 16(6) (2010) 1268-1279.

13. R. An, J. Zheng, Proximity to an exercise facility and physical activity in China, Southeast Asian Journal of Tropical Medicine and Public Health 45(6) (2014) 1483.

14. M. Su, Y.-y. Tan, Q.-m. Liu, Y.-j. Ren, I. Kawachi, L.-m. Li, J. Lv, Association between perceived urban built environment attributes and leisure-time physical activity among adults in Hangzhou, China, Preventive medicine 66 (2014) 60-64.

15. X. Cao, S.L. Handy, P.L. Mokhtarian, The influences of the built environment and residential selfselection on pedestrian behavior: evidence from Austin, TX, Transportation 33(1) (2006) 1-20.

16. D.G. Chatman, Residential choice, the built environment, and nonwork travel: evidence using new data and methods, Environment and planning A 41(5) (2009) 1072-1089. 
17. N.M. Wells, Y. Yang, Neighborhood design and walking: a quasi-experimental longitudinal study, American journal of preventive medicine 34(4) (2008) 313-319.

18. J. Montgomery, Making a city: Urbanity, vitality and urban design, Journal of urban design 3(1) (1998) 93-116.

19. A. Cuthbert, Designing Cities: Critical Readings on Urban Design. Malden, Oxford and Carlton: Blackwell Publishing, 2003.

20. B.C. Novia, W. Ratih, I.H. Bangun, Implementing Mixed Land Use Rooting Jane Jacobs' Concept of Diversity in Urban Sustainability, MODUL, 2017.

21. M.J. Greenwald, M.G. Boarnet, Built environment as determinant of walking behavior: Analyzing nonwork pedestrian travel in Portland, Oregon, Transportation research record 1780(1) (2001) 33-41.

22. M.G. Boarnet, M. Greenwald, T.E. McMillan, Walking, urban design, and health: toward a cost-benefit analysis framework, Journal of Planning Education and Research 27(3) (2008) 341-358.

23. P.F. Coogan, L.F. White, T.J. Adler, K.M. Hathaway, J.R. Palmer, L. Rosenberg, Prospective study of urban form and physical activity in the Black Women's Health Study, American journal of epidemiology 170(9) (2009) 1105-1117.

24. J. Boone-Heinonen, D.K. Guilkey, K.R. Evenson, P. Gordon-Larsen, Residential self-selection bias in the estimation of built environment effects on physical activity between adolescence and young adulthood, International Journal of Behavioral Nutrition and Physical Activity 7(1) (2010) 70.

25. S. Handy, X. Cao, P.L. Mokhtarian, Self-selection in the relationship between the built environment and walking: Empirical evidence from Northern California, Journal of the American Planning Association 72(1) (2006) 55-74.

26. S.L. Handy, X. Cao, P.L. Mokhtarian, The causal influence of neighborhood design on physical activity within the neighborhood: evidence from Northern California, American Journal of Health Promotion 22(5) (2008) 350-358.

27. X.J. Cao, P.L. Mokhtarian, S.L. Handy, The relationship between the built environment and nonwork travel: A case study of Northern California, Transportation Research Part A: Policy and Practice 43(5) (2009) 548-559.

28. Y. Gao, \& Liu, K, Planning for Diverse Slow Activities of Shenzhen Greenway, Planner 35(14) (2019) 7.

29. H. Meurs, R. Haaijer, Spatial structure and mobility, Transportation Research Part D: Transport and Environment 6(6) (2001) 429-446.

30. F. Li, Physical activity and health in the presence of China's economic growth: meeting the public health challenges of the aging population, Journal of Sport and Health Science 5(3) (2016) 258-269.

31. A. Forsyth, J.M. Oakes, K.H. Schmitz, M. Hearst, Does residential density increase walking and other physical activity?, Urban Studies 44(4) (2007) 679-697.

32. R. An, J. Shen, Q. Yang, Y. Yang, Impact of built environment on physical activity and obesity among children and adolescents in China: a narrative systematic review, Journal of sport and health science 8(2) (2019) 153-169. 
33. T.-L. Chen, H.-W. Chiu, Y.-F. Lin, How do East and Southeast Asian Cities Differ from Western Cities? A Systematic Review of the Urban Form Characteristics, Sustainability 12(6) (2020) 2423.

34. S. Rana, J. Morley, Surface networks, (2002).

35. L. Li, Q. DU, M. WENG, F. REN, Plotting of city spatial grid based on field mode, Geospatial Inf 6(2) (2008) 96-99.

36. Y. Song, D.A. Rodríguez, The measurement of the level of mixed land uses: a synthetic approach, Carolina Transportation Program White Paper Series, Chapel Hill, NC (2005).

37. P. Li, Y. Zhang, The size of the Chinese middle class, identity and social attitudes, Society 28(2) (2008) 1-19.

38. T. Hanibuchi, I. Kawachi, T. Nakaya, H. Hirai, K. Kondo, Neighborhood built environment and physical activity of Japanese older adults: results from the Aichi Gerontological Evaluation Study (AGES), BMC public health 11(1) (2011) 657.

39. M. Yang, M.W. Rosenberg, J. Li, Spatial variability of health inequalities of older people in China and related health factors, International journal of environmental research and public health 17(5) (2020) 1739.

40. L. Ying, Z. Yin, Quantitative evaluation on street vibrancy and its impact factors: A case study of Chengdu, New Archit 1 (2016) 52-57.

41. F. Jianxi, Y. Zhenshan, Factors influencing travel behavior of urban elderly people in Nanjing, Progress in Geography 34(12) (2015) 1598-1608.

42. L. Feidong, T. Shaohua, Built environment's influence on physical activity: Review and thought, Urban Planning International 30(2) (2015) 62-70.

43. Y. Huang, M. Rosenberg, L. Hou, M. Hu, Relationships among environment, climate, and longevity in China, International Journal of Environmental Research and Public Health 14(10) (2017) 1195.

44. G.W. Heath, R.C. Brownson, J. Kruger, R. Miles, K.E. Powell, L.T. Ramsey, The effectiveness of urban design and land use and transport policies and practices to increase physical activity: a systematic review, Journal of physical activity and health 3(s1) (2006) S55-S76.

45. C.E. Little, Greenways for America, JHU Press1995.

46. G. Lindsey, Use of urban greenways: insights from Indianapolis, Landscape and urban planning 45(23) (1999) 145-157.

\section{Figures}




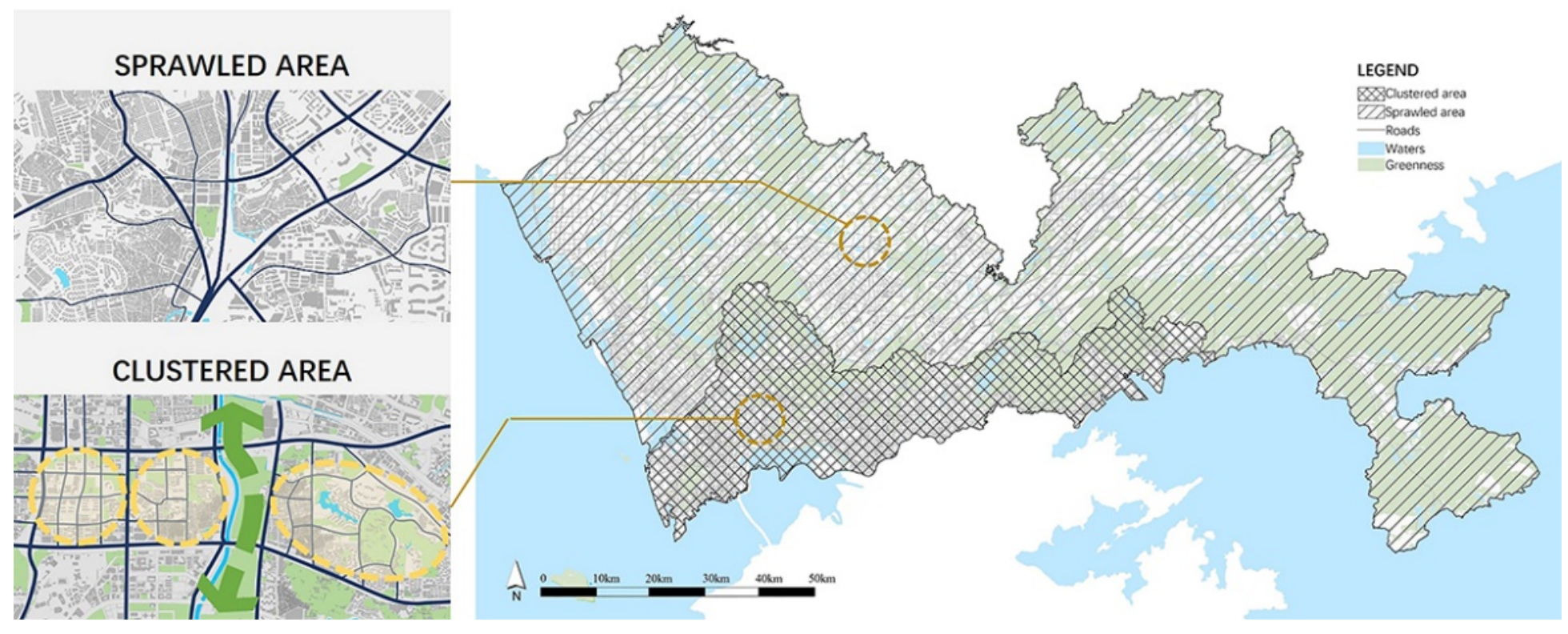

Figure 1

Schematic diagram of Shenzhen second-line custom. Note: The designations employed and the presentation of the material on this map do not imply the expression of any opinion whatsoever on the part of Research Square concerning the legal status of any country, territory, city or area or of its authorities, or concerning the delimitation of its frontiers or boundaries. This map has been provided by the authors.

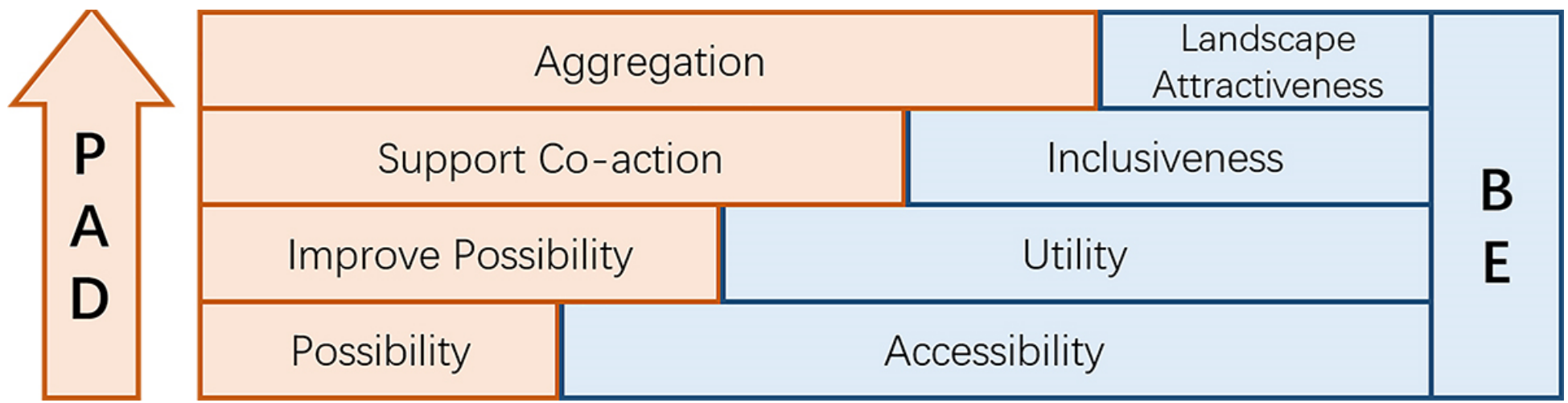

Figure 2

Research framework. 


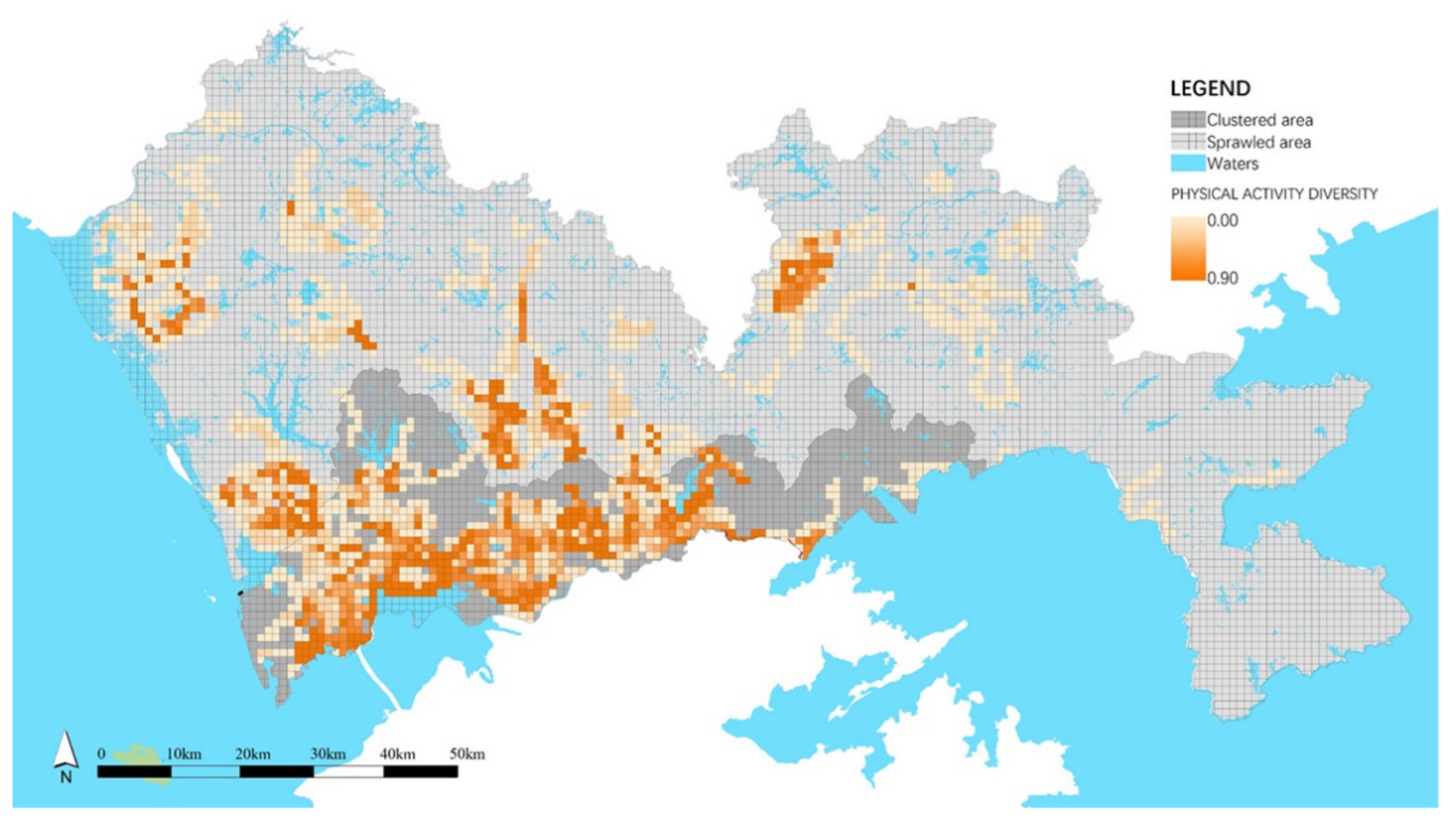

\section{Figure 3}

Spatial distribution of PAD. Note: The designations employed and the presentation of the material on this map do not imply the expression of any opinion whatsoever on the part of Research Square concerning the legal status of any country, territory, city or area or of its authorities, or concerning the delimitation of its frontiers or boundaries. This map has been provided by the authors. 


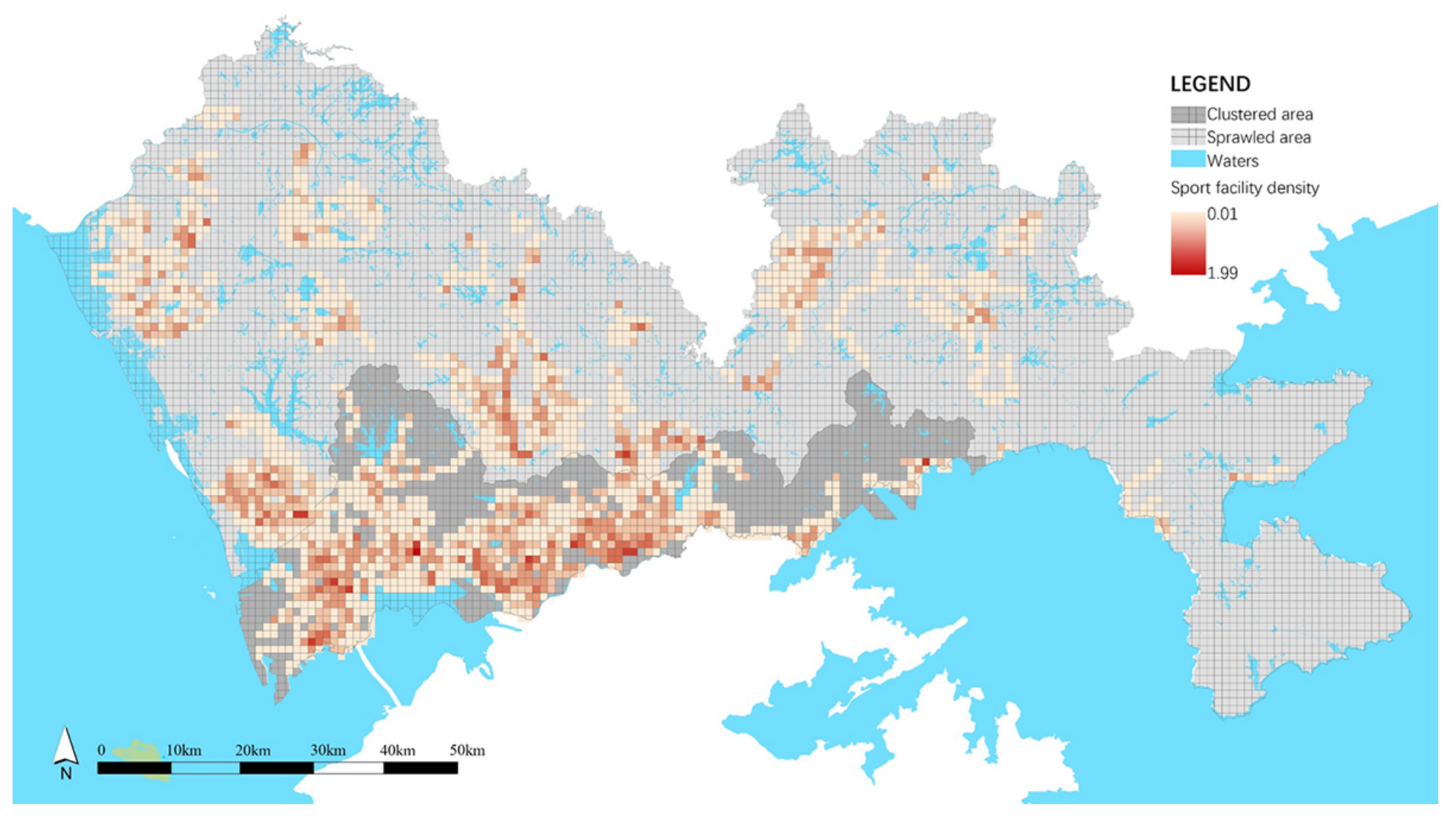

Figure 4

Spatial distribution of sports facility density. Note: The designations employed and the presentation of the material on this map do not imply the expression of any opinion whatsoever on the part of Research Square concerning the legal status of any country, territory, city or area or of its authorities, or concerning the delimitation of its frontiers or boundaries. This map has been provided by the authors. 


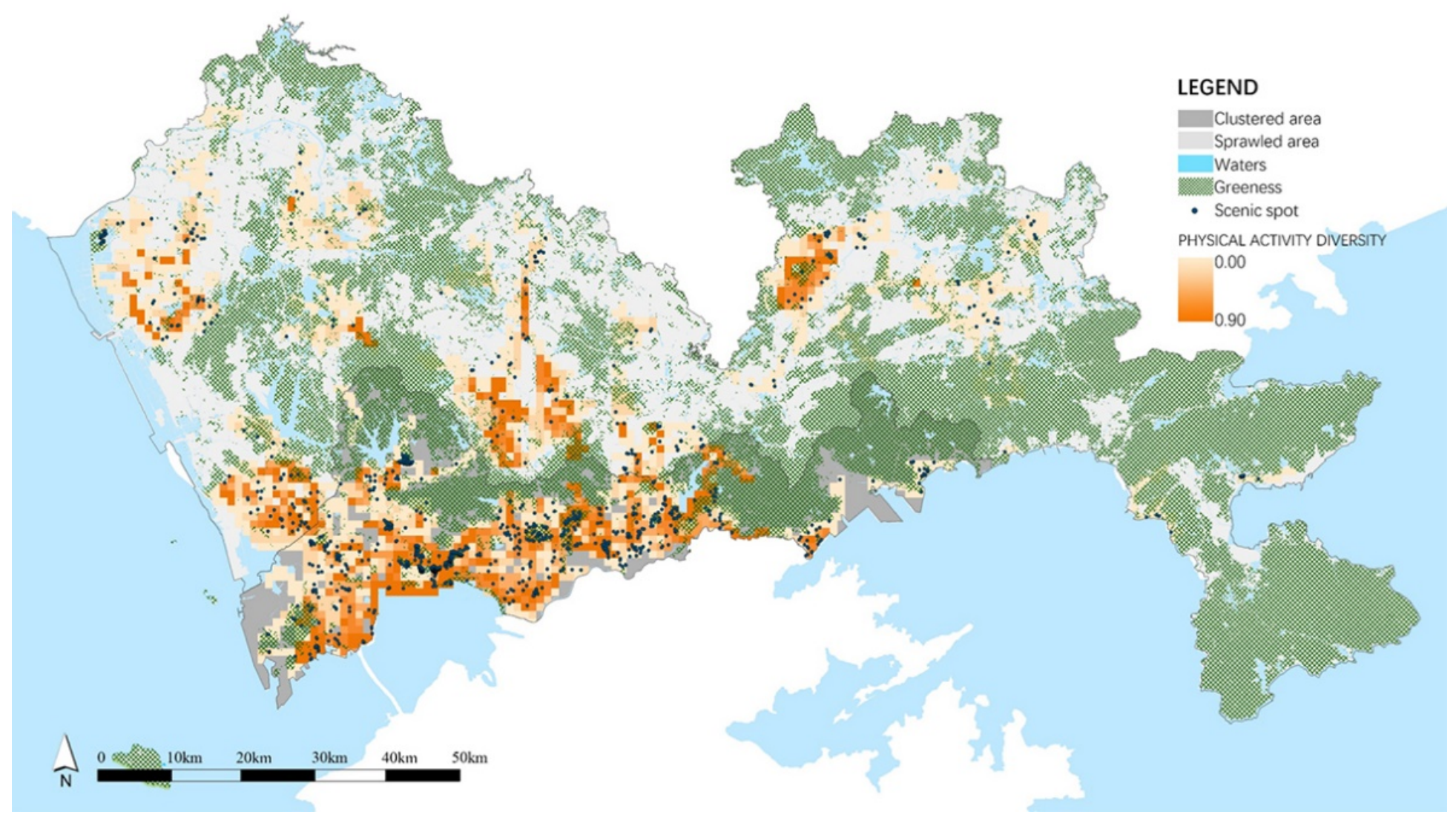

Figure 5

Spatial distribution of scenic spots. Note: The designations employed and the presentation of the material on this map do not imply the expression of any opinion whatsoever on the part of Research Square concerning the legal status of any country, territory, city or area or of its authorities, or concerning the delimitation of its frontiers or boundaries. This map has been provided by the authors.

\section{Progress 3: Landscape Attraction}

\section{Progress 2: Inclusiveness}

\section{Progress 1: accessibility}

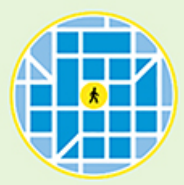

Place accessibility

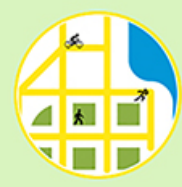

Service and sports facilities

Co-action of various PAs

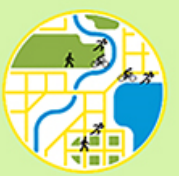

Landscape attractions

\section{Aggregation of various PAs}

Start-up of various PAs

Figure 6 
The progressive mechanism of built environment on supporting PAD.

\section{Supplementary Files}

This is a list of supplementary files associated with this preprint. Click to download.

- AppendixCalculationmethodofthephysicalactivityparticipantssocialclassdiversityPAPD.docx 